\title{
Identifikasi dan Penentuan Kadar Klorin pada Beras yang Dijual di Pasar Raya Padang
}

\author{
Suci Aulia Yude ${ }^{1}$, Yuniar Lestari ${ }^{2}$, Endrinaldi $^{3}$
}

\begin{abstract}
Abstrak
Keamanan makanan merupakan salah satu masalah yang harus mendapatkan perhatian terutama di negara berkembang seperti Indonesia, karena bisa berdampak buruk terhadap kesehatan. Penyebabnya adalah masih rendahnya pengetahuan, keterampilan serta tanggung jawab daripada produsen dan distributor pangan terhadap mutu serta keamanan makanan. Hal ini menyebabkan produsen dan distributor sering menambahkan bahan kimia ke dalam produk makanan, salah satunya penambahan klorin pada beras. Konsumsi klorin terus-menerus dapat menyebabkan gangguan pada saluran cerna, seperti gastritis. Tujuan penelitian ini adalah mengidentifikasi dan penentuan kadar klorin pada beras yang dijual di Pasar Raya Padang. Penelitian ini merupakan penelitian deskriptif yang dilakukan di Laboratorium Kimia Fakultas Kedokteran Universitas Andalas Padang dari Januari sampai April 2014. Identifikasi dan penentuan kadar klorin dilakukan terhadap 34 sampel beras yang diambil secara random. Metoda yang digunakan adalah metoda iodometri dan menggunakan larutan titrasi Na2S2O3 0,01 N. Hasil penelitian yang dilakukan terhadap 34 sampel, didapatkan 2 sampel beras yang mengandung klorin dengan kadar 0,35gr\% dan 0,53gr\%.
\end{abstract}

Kata kunci: klorin, beras, titrasi

\begin{abstract}
The food safety is one of problems that should get attention, especially in developing countries like Indonesia, because it can gives a negative impact for health. The cause is the producer's and the distributor's lack of knowledge, skill, and responsibility for the quality and safety of food. It causes producers and distributors often add chemicals to food products, one of which chlorine in the rice. Cotinuous consumption of chlorine can cause gastrointestinal tract disease like gastritis. The objective of this study was to identify and determination chlorine in the rice that sold at Pasar Raya Padang. This research is a descriptive study at The Chemistry Laboratory, Medical Faculty Andalas University Padang from January to April 2014. The identification and determination of chlorine on 34 samples of rice taken by random. The method used is iodometri method using a titration solution of $\mathrm{Na}_{2} \mathrm{~S}_{2} \mathrm{O}_{3} 0,01 \mathrm{~N}$. The results of the research showed that 2 of 34 samples of rice contain chlorine, the contents are 0,35gr\% and 0,53gr\%.
\end{abstract}

Keywords: chlorine, rice, titration

\footnotetext{
Affiliasi penulis: 1. Prodi Profesi Dokter FK UNAND (Fakultas Kedokteran Universitas Andalas Padang), 2. Bagian IImu Kesehatan Masyarakat FK UNAND, 3. Bagian Kimia FK UNAND.

Korespondensi: Suci Aulia Yude, Email :

yude_suci.ay44@yahoo.com, Telp: 085274660960
}

\section{PENDAHULUAN}

Keamanan makanan merupakan masalah yang harus mendapatkan perhatian khusus dalam penyelenggaraan kesehatan secara keseluruhan. Salah satu masalah keamanan makanan di Indonesia adalah masih rendahnya pengetahuan, keterampilan, dan tanggung jawab produsen dan distributor pangan tentang mutu dan keamanan makanan. Hal ini menyebabkan produsen dan distributor sering menambahkan bahan kimia ke dalam produk makanan, salah satunya penambahan klorin pada beras. Penggunaan bahan kimia pada makanan membuat keamanan pangan tersebut menjadi tidak terjamin. ${ }^{1}$ 
Keamanan pangan merupakan faktor terpenting yang harus diperhatikan untuk mendapatkan makanan yang bebas dari kerusakan, pemalsuan dan kontaminasi, baik yang disebabkan oleh mikroba atau senyawa kimia. ${ }^{2}$ Salah satu zat kimia tersebut adalah klorin yang biasa digunakan sebagai pemutih. Namun kini klorin bukan hanya digunakan untuk bahan pemutih pada pakaian dan kertas saja, tetapi telah digunakan sebagai bahan pemutih/pengilat beras, agar beras yang standar medium terlihat seperti beras berkualitas super. Klorin akan bereaksi dengan air yang dapat merusak sel-sel di dalam tubuh. Klorin berwujud gas berwarna kuning kehijauan dengan bau cukup menyengat. Dampak dari beras yang mengandung klorin itu tidak terjadi sekarang. Bahaya untuk kesehatan baru akan muncul 15 hingga 20 tahun mendatang, khususnya apabila beras yang mengandung klorin dikonsumsi secara terusmenerus. $^{3}$ Klorin dapat menyebabkan penyakit gastritis karena bersifat korosif. Bahan-bahan yang bersifat korosif dapat merusak sawar pelindung pada mukosa lambung yang menyebabkan lambung retan terhadap penyakit gastritis. ${ }^{4}$

Penelitian yang dilakukan oleh Dinas Perindag, Balai Pengawasan Obat dan Makanan (BPOM) serta Balai Pengujian dan Sertifikasi Mutu Barang (BPSBM) Sumatera Utara menemukan 1 dari 19 sampel beras yang diambil dari pengecer, gudang beras, serta kilang padi di Medan, Deli Serdang, dan Serdang Bedagai, positif mengandung klorin. Di lain pihak, Balai Pengawasan Obat dan Makanan Kota Tanggerang menemukan kadar klorin seberat 0,05 ppm dalam beras curah yang diperdagangkan di pasar tradisional Tanggerang. ${ }^{5}$

Berdasarkan Permenkes RI No. 772/Menkes/Per/IX/1988 tentang Bahan Tambahan Pangan, menyatakan bahwa klorin tidak termasuk ke dalam bahan tambahan pangan yang diizinkan penggunaannya dalam makanan. ${ }^{6}$ Karena hal-hal tersebut maka pada penelitian ini akan dilakukan identifikasi dan penentuan kadar klorin pada beras yang dijual di Pasar Raya Kota Padang karena kemungkinan beras tersebut juga mengandung klorin.

Penelitian ini bertujuan untuk identifikasi dan penentuan kadar klorin pada beras yang dijual di Pasar Raya Kota Padang.

\section{METODE}

Jenis penelitian ini merupakan penelitian deskriptif yang dilakukan di laboratorium kimia Fakultas Kedokteran Universitas Andalas Padang pada bulan Januari 2014 sampai April 2014. Sampel beras pada penelitian ini berjumlah 34 sampel, yang berasal dari 17 kios penjual beras di Pasar Raya Padang. 34 sampel beras yang diambil terbagi atas 17 beras yang berasal dari dalam Provisi Sumatera Barat (Sumbar) dan 17 sampel lainnya berasal dari luar Sumbar. Pengambilan sampel dilakukan dengan teknik random sampling. Pemeriksaan sampel menggunakan Metode lodometri.

\section{HASIL}

Penelitian yang telah dilakukan terhadap 34 sampel beras mendapatkan hasil yang dapat dilihat pada tabel di bawah ini.

Tabel 1. Identifikasi dan penetapan kadar klorin pada beras yang dijual di Pasar Raya Kota Padang.

\begin{tabular}{lcc}
\hline \multicolumn{1}{c}{ Sampel } & Jumlah & $\%$ \\
\hline $\begin{array}{l}\text { Mengandung } \\
\text { Klorin }\end{array}$ & 2 & 5,9 \\
Tidak & & \\
$\begin{array}{l}\text { Mengandung } \\
\text { Klorin }\end{array}$ & 32 & 94,1 \\
\hline
\end{tabular}

Berdasarkan Tabel 1 dapat dilihat bahwa 5,9\% dari seluruh sampel beras yang diperiksa, positif mengandung klorin. Sampel beras yang positif mengandung klorin dilanjutkan dengan penentuan kadar klorin yang terkandung. Kedua sampel yang positif tersebut merupakan beras yang berasal dari luar Sumbar serta mengandung klorin sebesar $0,35 \mathrm{gr} \%$ dan $0,53 \mathrm{gr} \%$.

\section{PEMBAHASAN}

Hasil penelitian ini menemukan 5,9\% dari seluruh sampel beras terbukti positif mengandung klorin. Sampel beras yang mengandung klorin tersebut adalah sampel B4 dengan kadar klorin sebesar 0,35gr\% dan sampel B12 dengan kadar klorin sebesar $0,53 \mathrm{gr} \%$. Hal ini bertentangan dengan Permenkes 
No.772/Menkes/Per/XI/88 yang menyebutkan bahwa klorin tidak diperbolehkan penggunaannya dalam makanan. Kedua sampel yang terdeteksi mengandung klorin berasal dari luar Sumbar, sedangkan beras yang berasal dari dalam Sumbar tidak ada yang terdeteksi mengandung klorin. Hal ini mungkin disebabkan oleh waktu yang ditempuh oleh sampel untuk sampai ke tangan pedagang. Beras yang didatangkan dari luar Sumbar membutuhkan waktu lebih lama dibandingkan beras yang berasal dari dalam Sumbar untuk sampai ke tangan pedagang di Pasar Raya Padang. Hal ini memungkinan dilakukannya pemberian klorin oleh pemasok ataupun pedagang sendiri agar beras tetap terlihat putih walaupun beras tersebut sebenarnya sudah kuning karena sudah lama.

Faktor waktu tempuh yang dibutuhkan masingmasing beras untuk sampai kepada pedagang di pasaran, putaran waktu penjualan juga mempengaruhi kemungkinan pemberian klorin pada beras. Putaran waktu penjualan beras yang berasal dari dalam Sumbar lebih cepat dibanding putaran waktu penjualan beras luar Sumbar. Hal ini disebabkan mayoritas masyarakat yang membeli beras di Pasar Raya Padang akan lebih memilih beras yang berasal dari Sumbar. Akibatnya beras yang berasal dari dalam Sumbar tidak tersimpan dalam waktu yang lama dan pedagang tidak perlu menambahkan klorin untuk memanipulasi beras lama menjadi putih kembali.

Hasil penelitian ini dapat menjadi masukan bagi BPOM dan instansi terkait lainnya untuk melakukan pengawasan secara berkala terhadap beras-beras yang dijual di pasaran. Pengawasan dilakukan agar beras yang kita konsumsi sehari-hari ini dapat terjamin mutu dan keamanannya. Dengan begitu kemungkinan terjadinya peningkatan insiden penyakit yang berhubungan dengan saluran pencernaan akibat mengkonsumsi beras berklorin di masa yang akan datang dapat dicegah.

\section{KESIMPULAN}

Ada 5,9\% dari sampel beras yang diperiksa, positif mengandung klorin dengan kadar sebesar $0,35 \mathrm{gr} \%$ dan $0,53 \mathrm{gr} \%$. Kedua sampel tersebut merupakan beras yang berasal dari luar Sumbar, sedangkan beras yang berasal dari dalm Sumbar tidak ada yang terdeteksi mengandung klorin.

\section{DAFTAR PUSTAKA}

1. WHO. Bahaya Bahan kimia pada kesehatan manusia dan lingkungan (terjemahan). Jakarta: EGC; 2006.

2. Adnan CA. Pangan dan gizi. Bogor: Sagung Seto; 2001.

3. Departemen Luar Negeri Republik Indonesia. Beras jernih dan licin bahayakan kesehatan lambung. 2007.

4. Guyton AC, Hall JE. Buku ajar fisiologi kedokteran (terjemahan). Jakarta: EGC; 2008.

5. Stefi. Beras putih berpemutih. Jakarta: Penerbit Bhratara; 2007.

6. Departemen Kesehatan RI, Peraturan menteri kesehatan RI No. 772/Menkes/PER/IX/1988, tentang bahan tambahan pangan. Jakarta: Departemen Kesehatan RI;1988. 